\title{
Estratégias pedagógicas no ensino de programação para mulheres
}

\author{
Caroline Sacramento Alves, Juliana Maria Oliveira dos Santos, Débora Abdalla
}

Departamento de Ciência da Computação - Universidade Federal da Bahia (UFBA) Grupo de Pesquisa e Extensão em Informática, Educação e Sociedade - Onda Digital Av. Adhemar de Barros, s/n - Ondina - CEP 40.170110 - Salvador, BA - Brasil

\{caroline.sacramento, juliana.maria, abdalla\}@ufba.br

\begin{abstract}
This paper presents the pedagogical strategies used in a beginner's computer programming course exclusively for women. In addition, it brings reflections on how such strategies enhance the teaching-learning process regarding the development of female interest in the field of computing. The courses are carried out by the Meninas Digitais - Regional Bahia project.
\end{abstract}

Resumo. Este artigo apresenta as estratégias pedagógicas utilizadas em um curso de iniciação à programação de computadores exclusivo para mulheres. Além disso, traz reflexões sobre como tais estratégias potencializam o processo de ensino-aprendizagem no que diz respeito ao desenvolvimento do interesse feminino pela área da computação. Os cursos são realizados pelo projeto Meninas Digitais - Regional Bahia.

\section{Introdução}

O mercado da Tecnologia da Informação (TI) está em constante expansão, trazendo-nos novidades a cada dia e demandando profissionais cada vez mais qualificados para atuarem na área. Dados do Censo da Educação Superior de 2019, realizado pelo Instituto Nacional de Estudos e Pesquisas Educacionais Anísio Teixeira (INEP), relatam que as mulheres ${ }^{1}$ representam $57 \%$ dos discentes matriculados em cursos de educação superior. Entretanto, apesar desse cenário, elas ainda são minoria em cursos da área de tecnologia, entre eles, os cursos relacionados a computação [INEP 2020].

Em um contexto mais específico, o relatório Educação Superior em Computação - Estatísticas 2019, realizado pela Sociedade Brasileira de Computação (SBC) aponta que, aproximadamente, $12 \%$ dos matriculados em cursos da área de computação pertencem ao sexo feminino e apenas $13 \%$ do total de concluintes são mulheres [SBC 2020]. Diante dessa perspectiva, o Curso de Iniciação à Programação de Computadores (CIProg) exclusivo para mulheres foi desenvolvido pelo projeto Meninas Digitais Regional Bahia, um dos pólos do programa nacional Meninas Digitais, em parceria com o Programa Onda Digital ${ }^{2}$ (POD) com o propósito de incentivar a participação e permanência feminina na computação por meio da programação.

\footnotetext{
${ }^{1}$ Os dados estatísticos apresentados levam em consideração as características biológicas herdadas no nascimento. De forma semelhante, o termo "mulher" utilizado durante este trabalho refere-se ao sexo feminino, não havendo uma análise acerca da identidade de gênero.

2 O Programa Onda Digital é um programa permanente de extensão do Departamento de Ciência da Computação da Universidade Federal da Bahia (UFBA).
} 


\section{O Curso de Iniciação à Programação de Computadores}

O CIProg tem sido ofertado desde 2013 pelo POD como parte das ações de extensão universitária. O curso tem como objetivo "apresentar noções iniciais de programação e desenvolver habilidades para resolução de problemas por meio de algoritmos e do raciocínio computacional" [Ferreira et al. 2016]. O planejamento do curso é feito pelos instrutores responsáveis pelas turmas - estudantes de graduação membros do POD - sob orientação dos professores coordenadores do projeto. A ementa do curso contempla os seguintes conteúdos: raciocínio lógico; algoritmos; tipos de variáveis; declaração de variáveis e constantes; instruções de entrada e saída; operadores aritméticos, relacionais e lógicos; estruturas de seleção; estruturas de repetição e vetores. A carga horária do curso é de 40h, com duração de 10 semanas.

Os recursos utilizados nas aulas são softwares livres. Dentre esses softwares livres, o Ambiente Virtual de Aprendizagem (AVA) Moodle é utilizado para hospedar os materiais das aulas, submeter atividades e servir como canal de comunicação oficial do curso. O aplicativo Telegram também funciona como uma ferramenta de comunicação alternativa, uma vez que o envio e recebimento de mensagens ocorre de forma instantânea. $\mathrm{O}$ ambiente de desenvolvimento integrado online Repl.it é um recurso utilizado para o desenvolvimento das atividades e projetos. Além disso, o sistema operacional presente nas máquinas é GNU/Linux.

\section{Metodologia}

Este trabalho consiste em um estudo exploratório de abordagem qualitativa. A metodologia utilizada consistiu nas seguintes etapas: 1. Levantamento estatístico e bibliográfico; 2. Coleta de dados; 3 . Envio de um questionário online para as ex-alunas; 4. Análise dos dados obtidos. A coleta de dados se deu por meio do processamento das informações presentes nas fichas de inscrição do CIProg e nas planilhas de gerenciamento das alunas matriculadas. Tais documentos foram disponibilizados pela coordenação do grupo de pesquisa e extensão. Além disso, foi considerada a opinião de algumas ex-alunas a partir de seus respectivos relatos de experiência, enviados por formulário criado para investigar a trajetória delas após o curso.

\section{Discussão e avaliação dos resultados}

As atividades descritas neste trabalho foram realizadas em duas turmas do CIProg Nível 1, em semestres letivos distintos: 2018.2 e 2019.1. Essas turmas foram escolhidas por serem as primeiras turmas a migrar da linguagem $\mathrm{C}$ para a linguagem $\mathrm{C}++$. Elas são, respectivamente, a Turma 7 e Turma 8 de acordo com a ordem cronológica em que os cursos foram ofertados. As inscrições para ambas as turmas foram realizadas através dos Editais de Seleção dos cursos, onde foram ofertadas apenas 8 vagas devido à quantidade de computadores disponíveis no local onde as aulas eram realizadas. Entretanto, em ambas as turmas, 11 alunas foram matriculadas pois algumas delas levaram seu próprio notebook para as aulas. 
As alunas matriculadas na Turma 7 pertenciam aos seguintes cursos de graduação: Arquivologia, Bacharelado Interdisciplinar ${ }^{3}$ em Ciência e Tecnologia, Biotecnologia, Comunicação Social - Jornalismo, Direito, Engenharia da Computação, Farmácia e Museologia. As alunas matriculadas na Turma 8 pertenciam aos seguintes cursos: BI em Artes, BI em Ciência e Tecnologia, Ciência da Computação, Comunicação, Letras, Matemática e Sistemas de Informação. Além disso, duas alunas não faziam parte da comunidade acadêmica, sendo egressas do ensino médio.

Em relação às concluintes, 6 alunas concluíram o CIProg na Turma 7. Os cursos de graduação aos quais pertenciam eram: BI em Ciência e Tecnologia, Comunicação Social - Jornalismo e Engenharia da Computação. A Turma 8, por sua vez, teve 9 concluintes. Elas faziam parte dos seguintes cursos: BI em Artes, BI em Ciência e Tecnologia, Ciência da Computação, Letras, Matemática e Sistemas de Informação. Além disso, uma das egressas do ensino médio também concluiu o curso com sucesso.

Embora não fosse exigido das alunas conhecimentos prévios em programação de computadores, é possível observar que alunas anteriormente envolvidas com ciência e tecnologia tiveram menor evasão no curso. Como a relação de aproximação das alunas com os conteúdos abordados durante o curso ocorre, em grande parte, da consciência que a própria aluna desenvolve sobre o sucesso do seu processo de aprendizagem, é essencial uma atuação eficiente e eficaz das instrutoras na mediação pedagógica, utilizando estratégias que aumentem as chances de aprendizagem da aluna [Leite 2012]. A Tabela 1 apresenta, resumidamente, as estratégias pedagógicas utilizadas nas aulas.

Tabela 1. Quadro-resumo das estratégias pedagógicas utilizadas nas aulas

\begin{tabular}{|c|c|c|c|c|c|c|}
\hline & $\begin{array}{c}\text { Aula } \\
\text { expositiva }\end{array}$ & Exercícios & $\begin{array}{c}\text { Coding } \\
\text { Dojo }\end{array}$ & $\begin{array}{c}\text { Tutoria: } \\
\text { exercícios }\end{array}$ & $\begin{array}{c}\text { Tutoria: } \\
\text { projeto final }\end{array}$ & $\begin{array}{c}\text { Acompanhamento } \\
\text { pedagógico }\end{array}$ \\
\hline Turma 7 & $\checkmark$ & $\checkmark$ & $x$ & $\checkmark$ & $X$ & $X$ \\
\hline Turma 8 & $\checkmark$ & $\checkmark$ & $\checkmark$ & $\checkmark$ & $\checkmark$ & $\checkmark$ \\
\hline
\end{tabular}

As estratégias utilizadas na Turma 8 foram adaptadas com o auxílio de uma pedagoga da Coordenação Pedagógica do Grupo de Pesquisa e Extensão Onda Digital professora visitante em formação de pós-doutorado na UFBA. Sendo o aprendizado um processo ativo e construtivo, para adquirir novos conhecimentos as alunas precisam integrar as novas informações apresentadas durante o curso com as ideias e habilidades que já eram sabidas, construindo um significado para o aprendizado [Smith \& MacGregor 1992]. Diante desse contexto, todo o auxílio fornecido pela Doutora em Educação no planejamento e execução das aulas favoreceu essa construção de significado pelas estudantes, contribuindo para o sucesso do processo de aprendizagem.

Em ambas as turmas, a correção das atividades era feita de forma manual, onde a lógica de cada aluna era valorizada. Além disso, na Turma 8 também houve o acompanhamento do projeto final desde a concepção da ideia até o tratamento de erros no código fonte do programa. Geralmente, cada instrutora acompanha de 2 a 3 alunas

\footnotetext{
${ }^{3}$ O Bacharelado Interdisciplinar (BI) é uma modalidade de graduação oferecida pela UFBA que permite uma formação interdisciplinar mais ampla e flexível (http://www.ihac.ufba.br/ensino/graduacao/).
} 
por turma, sem considerar as eventuais evasões. As instrutoras foram orientadas a demonstrar paciência e compreensão com as estudantes, além de assumir uma postura informal, descontraída e não-autoritária [Ferreira et al. 2016]. Acredita-se que a mediação pedagógica também é de natureza afetiva, de tal forma produz impactos na relação entre as alunas e os conteúdos que são apresentados [Leite 2012].

A inserção da prática de Coding Dojo funcionou como uma maneira de estimular a aprendizagem colaborativa em sala de aula através da resolução de problemas em conjunto. $\mathrm{O}$ engajamento mútuo durante as práticas proporcionou $\mathrm{o}$ desenvolvimento constante de habilidades como raciocínio lógico e trabalho em equipe. A aprendizagem colaborativa é social e intelectualmente envolvente por natureza, uma vez que convida as alunas a estabelecer conexões mais próximas com suas colegas, suas instrutoras e sua aprendizagem [Smith \& MacGregor 1992].

Ainda é importante ressaltar que o corpo de instrutores de ambas as turmas era formado exclusivamente por mulheres. Isso reforça o estímulo à presença feminina na computação por meio da representatividade em sala de aula, uma vez que a falta de divulgação de exemplos femininos encorajadores é um dos obstáculos para a inserção das mulheres na área [Citeli 2015], "desestimulando sua identificação pessoal com as carreiras científicas" [Louzada et al. 2019]. Em 2021, foi possível colher relatos de algumas ex-alunas sobre o impacto do CIProg em suas vidas:

\begin{abstract}
"Foi a porta de entrada para o mundo da programação e me fez ter muito gosto pela área. Tanto que fiz o segundo nível [...] e até hoje me aventuro por novas linguagens, pensando até em trabalhar com programação, se for o caso. Ter a oportunidade de aprender com mulheres foi muito inspirador." Aluna de Comunicação Social Jornalismo (Turma 7)

“Não só o curso como o projeto Meninas Digitais Regional Bahia como um todo teve um grande impacto na minha vida. Através deles pude finalmente entender o que eu queria para meu futuro profissional: ser uma programadora. [...]. Sinto que era como uma rede de apoio, estávamos lá para aprender e dialogar não só sobre programação, como também sobre nossa vivência como mulher nessa área.” Aluna do BI em Ciência e Tecnologia e membra do Meninas Digitais - Regional Bahia (Turma 8)

"Foi uma experiência incrivel poder aprender algo novo e conviver com tantas mulheres inspiradoras, que me motivaram em diversos sentidos além do do curso em si. A participação nesse curso foi essencial para a escolha do curso na faculdade." Aluna do BI em Ciência e Tecnologia e ex-aluna da comunidade externa (Turma 8)
\end{abstract}

A participação de mulheres de diferentes cursos de graduação contribuiu para “o empoderamento e inserção profissional feminina para além da informática" [Louzada et al. 2019]. Contudo, apesar do impacto que as ações de incentivo como o CIProg causam, "ainda há muito trabalho a ser feito para alcançar a equidade de gênero dentro deste espaço" [Cesario et al. 2017].

\title{
5. Considerações finais
}

As análises realizadas apontam que as estratégias pedagógicas realizadas em sala de aula tiveram grande influência na relação de aproximação ou de afastamento das alunas em relação aos conteúdos abordados. Considerando os perfis apresentados, percebe-se que o maior desafio é a retenção de alunas de áreas não relacionadas à ciência $\mathrm{e}$ tecnologia, uma vez que todas as não-concluintes do curso atuavam em outras áreas. 
Entretanto, as turmas tiveram um número muito pequeno de participantes, e consequentemente, isso não garante a generalização de conclusões, podendo ser uma questão a ser tratada em trabalhos futuros.

Em virtude de todos os pontos apresentados acerca da participação feminina na computação, é imperativo que o projeto Meninas Digitais - Regional Bahia continue promovendo ações direcionadas ao rompimento dos paradigmas relacionados à discrepância de gênero na área. Nesse contexto, reforça-se a necessidade de estabelecer a representatividade feminina na computação por meio das diversas ações realizadas pelo projeto, que vão além dos cursos de programação, como rodas de conversa, mesas redondas, palestras e workshops. Ademais, espera-se que o impacto das atividades realizadas provoquem a reflexão do papel de agente transformador que cada um desempenha no cotidiano e implique na atuação do projeto como norteador para criação de novas iniciativas parceiras.

\section{Referências}

Cesario, G., da Silveira, N., Bim, S., \& Maciel, C. (2017). Por Mais Mulheres na Computação: análise dos trabalhos publicados no $\mathrm{X}$ Women in Information Technology. In Anais do XI Women in Information Technology, p. 1214-1217.

Citeli, M. T. (2015). Mulheres nas ciências: mapeando campos de estudo. In Cadernos Pagu, n. 15, p. 39-75.

Ferreira, A., Santos, J., Silva, R., Oliveira, A., Zabot, D., Abdalla, D., \& Matos, E. (2016). Hello World: relato de experiência de um curso de iniciação à programação. In Anais dos Workshops do V Congresso Brasileiro de Informática na Educação, p. 1306-1315.

Instituto Nacional de Estudos e Pesquisas Educacionais Anísio Teixeira. (2020). Sinopse Estatística da Educação Superior 2019, http://inep.gov.br/sinopses-estatisticas-da-educacao-superior, Março 2021.

Leite, S. (2012). Afetividade nas práticas pedagógicas. In Temas em Psicologia, v. 20, n. 2, p. 355-368.

Louzada, N., Santana, T., Assis, I., Braga, R., \& Braga, A. (2019). Agindo sobre a diferença: atividades de empoderamento feminino em prol da permanência de mulheres em cursos de Tecnologia da Informação. In Anais do XIII Women in Information Technology, p. 69-78.

Smith, B. L. \& MacGregor, J. (1992). What is collaborative learning? In Collaborative Learning: A Sourcebook for Higher Education, A. Goodsell, M. Maher, V. Tinto, B. L. Smith \& J. MacGregor. University Park: National Center on Postsecondary Teaching, Learning and Assessment, p. 9-22.

Sociedade Brasileira de Computação. (2020). Educação Superior em Computação $\begin{array}{lll}\text { Estatísticas } & - & 2019,\end{array}$ https://www.sbc.org.br/documentos-da-sbc/summary/133-estatisticas/1324-educacao -superior-em-computacao-estatisticas-2019, Março 2021. 